Clinical Study

\title{
Preliminary Clinical Experience of trans-1-Amino-3-(18)F-fluorocyclobutanecarboxylic Acid (anti-(18)F-FACBC) PET/CT Imaging in Prostate Cancer Patients
}

\author{
Kalevi Kairemo, ${ }^{1}$ Nigora Rasulova, ${ }^{1}$ Kaarina Partanen, ${ }^{2}$ and Timo Joensuu ${ }^{3}$ \\ ${ }^{1}$ Department of Molecular Radiotherapy \& Nuclear Medicine, Docrates Cancer Center, Saukonpaadenranta 2, 00180 Helsinki, Finland \\ ${ }^{2}$ Department of Radiology, Docrates Cancer Center, Saukonpaadenranta 2, 00180 Helsinki, Finland \\ ${ }^{3}$ Department of Medical Oncology and Clinical Radiotherapy, Docrates Cancer Center, Saukonpaadenranta 2, 00180 Helsinki, Finland
}

Correspondence should be addressed to Kalevi Kairemo; kalevi.kairemo@docrates.com

Received 27 January 2014; Revised 9 April 2014; Accepted 12 May 2014; Published 1 June 2014

Academic Editor: Giampiero Giovacchini

Copyright (C) 2014 Kalevi Kairemo et al. This is an open access article distributed under the Creative Commons Attribution License, which permits unrestricted use, distribution, and reproduction in any medium, provided the original work is properly cited.

Background. In this retrospective analysis we assessed the role of $\left[{ }^{18} \mathrm{~F}\right]$-FACBC-PET/CT in the prostatic cancer staging. Procedure. 30 first $\left[{ }^{18} \mathrm{~F}\right]$-FACBC-PET/CT images of 26 patients (68.1 \pm 5.8 years) were analyzed. PET/CT findings were compared with PSA concentrations, with PSA doubling times (PDT), and with correlative imaging. Results. On $16\left[{ }^{18} \mathrm{~F}\right]$-FACBC (53.3\%) scans, 58 metabolically active lesions were found. $12(20.7 \%)$ lesions corresponding to the local relapse were found in prostate/prostate bed and seminal vesicles, $9(15.5 \%)$ lesions were located in regional lymph nodes, 10 (17.2\%) were located in distal lymph nodes, and 26 (44.8\%) metabolically active lesions were found in the skeleton. In one case, focal uptake was found in the brain, confirmed further on MRI as meningioma. The mean S-PSA level in patients with positive $\left[{ }^{18} \mathrm{~F}\right]-\mathrm{FACBC}$ findings was $9.5 \pm 16.9 \mu \mathrm{g} / \mathrm{L}(0.54-69 \mu \mathrm{g} / \mathrm{L})$ and in patients with negative $\left[{ }^{18} \mathrm{~F}\right]$-FACBC findings was $1.96 \pm 1.87 \mu \mathrm{g} / \mathrm{L}(0.11-5.9 \mu \mathrm{g} / \mathrm{L})$, but the difference was not statistically significant. However, the PSA doubling time (PDT) in patients with positive findings was significantly shorter than PDT in patients with negative findings: $3.25 \pm 2.09$ months $(0.3-6$ months) versus $31.2 \pm 22.02$ months $(8-84$ months), $P<0.0001$. There was a strong positive correlation between PSA value and number of metabolically active lesions $(R=0.74)$ and a negative correlation between PDT and number of metabolically active lesions $(R=-0.56)$. There was a weak negative correlation between PDT and $\mathrm{SUV}_{\max }(R=-0.30)$. Conclusion. According to our preliminary clinical experience, $\left[{ }^{18} \mathrm{~F}\right]$-FACBC-PET may play a role in in vivo restaging of an active prostate cancer, especially in patients with a short S-PSA doubling time.

\section{Introduction}

Trans-1-amino- $3-{ }^{18}$ F-fluorocyclobutanecarboxylic acid (anti- $\left.\left[{ }^{18} \mathrm{~F}\right]-\mathrm{FACBC}\right)$ is an amino acid positron emission tomography (PET) tracer that has shown promise for visualizing prostate cancer. This $\left[{ }^{18} \mathrm{~F}\right]-\mathrm{FACBC}$ tracer was developed for L-amino acid transport evaluation; it demonstrated favorable dosimetry, liver being the critical organ, and $14 \mu \mathrm{Sv} / \mathrm{MBq}$ effective dose was measured in 6 healthy volunteers in a first-in-man study [1]. Its safety, tracer stability, and uptake kinetics in patients have been reported in a phase I trial [2].
This tracer has been used in 10 prostate cancer patients before prostatectomy to find lesions in different prostate regions [3] and in another 10 patients to successfully separate malignant lung lesions from inflammatory pulmonary lesions [4].

In the literature, clinical results about its targeting ability in prostate cancer have also been superior as compared to Prostascint [5] and as compared to $\left[{ }^{11} \mathrm{C}\right]$-choline $[6,7]$. Anti-3- $\left[{ }^{18} \mathrm{~F}\right]$-FACBC demonstrated a sensitivity of $89 \%$ (36 patients) for cancer in the prostate bed and a sensitivity of $100 \%$ for detecting an extraprostatic recurrence (10 patients) [5]. 
$\left[{ }^{18} \mathrm{~F}\right]-\mathrm{FACBC}-\mathrm{PET}$ is believed to be useful not only for the visualization of human prostate cancer, but also for differentiating cancer from inflammation and from benign hyperplasia as studied in animals. Also, most of the mechanisms are known from cellular studies [8].

FACBC is not yet a registered radiopharmaceutical either in $\mathrm{EU}$ or in the US. Fluorocholine $(\mathrm{FCH})$ is a registered radiopharmaceutical in a few European countries, such as France, and it is considered currently the standard imaging agent for staging prostate cancer. According to the largest meta-analysis so far [9], the specificity of $\left[{ }^{18} \mathrm{~F}\right]-\mathrm{FCH}-\mathrm{PET}$ is high, but the sensitivity is low. Very little is known yet about the intraprostatic distribution of FCH and its role in T-staging [9].

The mechanism of $\left[{ }^{18} \mathrm{~F}\right]-\mathrm{FACBC}$ uptake is different as compared to that of fluorocholine. Both tracers are anabolic, but $\left[{ }^{18} \mathrm{~F}\right]-\mathrm{FACBC}$ is active in amino acid transport for protein synthesis, whereas $\mathrm{FCH}$ is participating in the phosphatidylcholine synthesis necessary for cell membrane renewal.

In cell lines, it has been shown that $\left[{ }^{18} \mathrm{~F}\right]-\mathrm{FACBC}$ is not incorporated into proteins in prostate cancer cells; and $(\mathrm{Na}+)$-dependent L-amino acid transport system is mainly responsible for the active mechanism of cellular uptake, whereas $(\mathrm{Na}+)$-independent transport mechanisms do not participate in cellular uptake [10]. In rat orthotopic model, this transport mechanism has been confirmed using the same cell line DU 145 as in the cellular mechanism studies [10]. Additionally, in a dual disease animal model both for inflammation and prostate cancer, it could be shown that $\left[{ }^{18} \mathrm{~F}\right]-\mathrm{FACBC}$ targets human prostate cancer and could separate cancer from inflammation [8]. However, all clinical reports are preliminary so far, and all investigators warrant further studies in clinical trials. The present analysis is the full report of our experience in 30 first clinical imaging examinations. Our main purpose in the present paper was to analyze the clinical suitability of $\left[{ }^{18} \mathrm{~F}\right]$-FACBC PET/CT for restaging of biochemical relapse in radically treated prostate cancer.

\section{Materials and Methods}

2.1. Patients. $30\left[{ }^{18} \mathrm{~F}\right]$-FACBC-PET/CT scans of 26 patients (25 with confirmed prostatic cancer in the period 1999-2013) were analyzed: age ranging from 56 to 77 years (mean age $68.1 \pm 5.8)$; Gleason score $5-9$ (mean $7.1 \pm 1.4)$; PSA value $0.11-69 \mu \mathrm{g} / \mathrm{L}$ (mean $7.9 \pm 14.6$ ). FACBC-PET/CT scans for restaging were done in 25 patients with confirmed prostatic cancer and in one patient with suspicion of prostate cancer.

12 patients had radical prostatectomy and following radiotherapy with a dose of 66-77 Gy, 13 patients received radical radiotherapy $66-77 \mathrm{~Gy} .20$ patients were receiving androgen deprivation therapy (ADT), 11 bisphosphonate therapy, 5 chemotherapy, and 7 Sm-153-EDTMP therapy, and 1 additionally had received denosumab (Xgeva). And only one patient was suspected for prostate cancer due to increased PSA level. The initial staging and the received treatments by patients are listed in Table 1.
This work is a retrospective analysis of our thirty first $\left[{ }^{18} \mathrm{~F}\right]$-FACBC-PET/CT images. $\left[{ }^{18} \mathrm{~F}\right]$-FACBC was used with a special permission for compassionate use from the Finnish Medical Evaluation Agency (FIMEA permission number $14863 / 2012$ ) for individual cancer management purposes at our institution. This analysis was performed according to the principles of the Declaration of Helsinki. Written informed consent was obtained from all patients, and our patient database was approved by the Finnish authority for the protection of privacy and personal data in clinical research.

2.2. Imaging PET/CT Protocol. Examination was done on Siemens Biograph PET Scanner, combined with low-dose CT. The injected activity dose of $\left[{ }^{18} \mathrm{~F}\right]$-anti-FACBC ranged from 230 to $320 \mathrm{MBq}$ (mean $328 \pm 56.8$ ). Early imaging was performed by starting at $8.0 \pm 3.0 \mathrm{~min}$ (range of $4-16 \mathrm{~min}$ ) from pelvic region using $3 \mathrm{~min}$ per bed position imaging protocol followed by whole body imaging from the calvarium to the midthighs at $23.4 \pm 6.3 \mathrm{~min}$ (range of $16-37 \mathrm{~min}$ ) using 3 min per bed position. The tracer was purchased from Uppsala (Uppsala Imanet, Sweden), and the production has been described by Sörensen et al. [2].

2.3. Image Analysis. Lesions were considered abnormal when focal tracer accumulation was more than $30 \%$ greater than normal organ activity. (1) Diagnosis of malignant lymph nodes on $\left[{ }^{18} \mathrm{~F}\right]$-FACBC-PET images was based on visual assessment. (2) Lymph nodes were considered benign if they were not larger than $10 \mathrm{~mm}$ on CT scans and without abnormal $\left[{ }^{18} \mathrm{~F}\right]$-FACBC uptake. (3) Interpretation of malignant or benign bone lesions depended on the anatomical localization, and the presence/absence of $\left[{ }^{18} \mathrm{~F}\right]$-FACBC uptake was compared with the findings of correlative imaging, such as CT, MRI, Na $\left[{ }^{18} \mathrm{~F}\right]-\mathrm{F}-\mathrm{PET} / \mathrm{CT}$, or $\left[{ }^{18} \mathrm{~F}\right]-\mathrm{FCH}-\mathrm{PET} / \mathrm{CT}$. The correlative imaging was counted if performed within 2 weeks from the $\left[{ }^{18} \mathrm{~F}\right]$-FACBC-PET/CT. These images were based on our clinical practice, not in any protocols. (4) In the prostate tissue, $\mathrm{SUV}_{\text {max }}$-value $3.5(\mathrm{mg} / \mathrm{mL})$ was considered as cut-off limit. Additionally, an increasing uptake to the late image from the early image in the prostate region was classified as pathological.

2.4. Statistical Analysis. The acquired results were expressed as the mean \pm SEM for each variable. Comparison of data among various groups was performed with Student's unpaired $t$-test. A $P<0.05$ was considered statistically significant. For calculating correlation between PSA, PSA doubling time DT (PDT), SUVs, and number of metabolically active lesions, Spearman rank correlation coefficient and simple linear regression for building the curves were used. In case of non-Gaussian distribution Mann-Whitney $U$ test was used.

\section{Results}

On $16\left[{ }^{18} \mathrm{~F}\right]$-FACBC-PET scans (53.3\%), a total of 58 metabolic active lesions were detected. In prostate, prostate bed and seminal vesicles focal uptake was found in 12 cases $\left(20.7 \%\right.$ ), with $\mathrm{SUV}_{\max }$ ranging from 3.7 to 7.2 (mean 


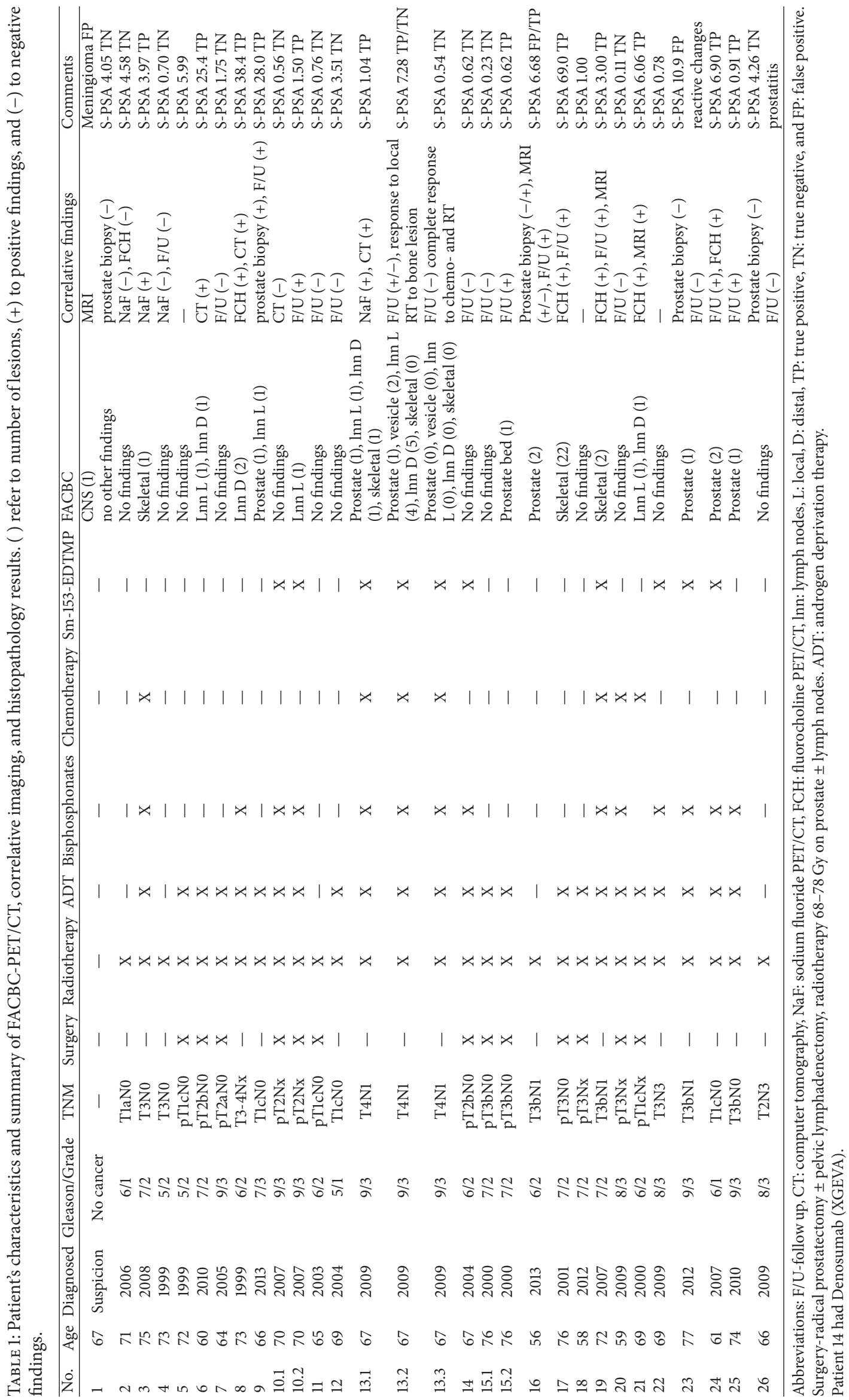


TABLE 2: PSA level and PSA doubling time in group of patients with positive and negative FACBC findings.

\begin{tabular}{|c|c|c|c|}
\hline \multicolumn{2}{|c|}{$\begin{array}{l}\text { Studies with positive }\left[{ }^{18} \mathrm{~F}\right] \text {-FACBC findings (I) } \\
\qquad\left(n=15^{*}\right)\end{array}$} & \multicolumn{2}{|c|}{$\begin{array}{l}\text { Studies with negative }\left[{ }^{18} \mathrm{~F}\right] \text {-FACBC findings (II) } \\
\qquad\left(n=15^{*}\right)\end{array}$} \\
\hline S-PSA level & S-PSA doubling time ${ }^{* *}$ & S-PSA level & S-PSA doubling time ${ }^{* *}$ \\
\hline $9.5 \pm 16.9(0.54-69 \mu \mathrm{g} / \mathrm{L})$ & $3.25 \pm 2.09$ months ( $0.3-6$ months) & $1.96 \pm 1.87 \mu \mathrm{g} / \mathrm{L}(0.11-5.99 \mu \mathrm{g} / \mathrm{L})$ & $31.2 \pm 22.02$ months ( $8-84$ months) \\
\hline
\end{tabular}

$5.07 \pm 1.9)$. In local lymph nodes, 9 lesions $(15.5 \%)$ were found with $\mathrm{SUV}_{\max } 4.1-10.7$ (mean $8.1 \pm 2.6$ ) and, in distal lymph nodes, 10 lesions (17.2\%) with $\mathrm{SUV}_{\max } 3.4-11.9$ (mean $7.35 \pm 2.7)$ were found. A total of 26 bone lesions $(44.8 \%)$ with $\mathrm{SUV}_{\max } 4.2-8.8$ (mean $5.4 \pm 0.7$ ) were observed. In one case, there was increased tracer uptake in the brain with a $\mathrm{SUV}_{\max } 8.1(1.7 \%)$ confirmed later on MRI as meningioma. The findings are presented for each patient individually in Table 1.

The mean PSA level in patients with negative $\left[{ }^{18} \mathrm{~F}\right]-$ FACBC-PET findings was $1.96 \pm 1.87 \mu \mathrm{g} / \mathrm{L}(0.11-5.99)$, whereas, with $\left[{ }^{18} \mathrm{~F}\right]$-FACBC positive PET findings, it was $9.5 \pm 16.9 \mu \mathrm{g} / \mathrm{L}(0.54-69)$. There was no statistically significant difference in the PSA values between patients with positive and negative findings $(P<0.2$, Mann-Whitney $U$ test). However, there was statistically significant difference in the PDTs in patients with positive findings $3.25 \pm 2.09$ months $(0.3-$ 6 months) versus PDTs in patients with negative findings $31.2 \pm 22.02$ months $(8-84$ months $)(P<0.0001)$ (Table 2$)$.

The correlations between PSA value and number of lesions, between PDT and number of lesions and between PDT and SUV $V_{\text {max }}$, are shown in Figure 1.

To illustrate the $\left[{ }^{18} \mathrm{~F}\right]$-FACBC-PET in clinical practice, two patients with multiple diagnostic imaging are presented. The patient (number 10 in Table 1) had a totally negative study at serum PSA concentration 0.56 , which turned positive 3 months later at serum PSA concentration 1.50 (Figure 2). Another patient (number 13 in Table 1) shows a successful treatment response evaluation by $\left[{ }^{18} \mathrm{~F}\right]$-FACBC-PET/CT follow-up (Figure 3).

\section{Discussion}

This synthetic FACBC amino acid, which is an isoleucine analogue, is developed for assessment of the anabolic component of tumor metabolism in clinical routine PET. The uptake of FACBC is mediated by the large-neutral amino acid transport system, and it is transported into cells but is not incorporated into proteins [8]. Because only a small amount of FACBC is excreted into the urinary system and because amino acid uptake is enhanced in malignancies, FACBC may play an essential role in the detection of prostate cancer. Its clinical utility is still unknown [11].

In the retrospective analysis of our clinical data, $\left[{ }^{18} \mathrm{~F}\right]-$ FACBC-PET showed its capability of targeting active prostate cancer in patients. Our patient numbers are still low, but our results support the previous findings [2-7]. The specificity seems to be high in these studies.

Results about characterizing prostate tissue in vivo have been reported in 10 patients with prostate carcinoma studied using $\left[{ }^{18} \mathrm{~F}\right]$-FACBC before prostatectomy [3]. In these patients, surgical specimen analysis was compared with the dynamic PET imaging results. 79 sextants had malignancy and 41 were benign: $\mathrm{SUV}_{\max }$ was significantly higher $(P<0.05)$ in malignant sextants (e.g., $4.0 \pm 1.3$ at $28 \mathrm{~min}$ ) compared to nonmalignant sextants (e.g., $3.4 \pm 0.9$ at $28 \mathrm{~min}$ ), although there was overlap between malignant and nonmalignant sextants. SUV $\mathrm{Smax}_{\max }$ also significantly correlated $(P<0.05)$ with Gleason score at all imaging time points (e.g., $r=0.46$ at $28 \mathrm{~min})$. Since there was no distinct separation between malignant and nonmalignant sextants or between Gleason score levels, the authors thought that FACBC alone was not good enough for radiation therapy planning but may be useful to guide the biopsy of the most aggressive lesion [3]. Similarly, surgical specimen analysis was performed in lung lesions in 10 patients [4], and anti-3-[ $\left.{ }^{18} \mathrm{~F}\right] \mathrm{FACBC}$ uptake in malignant lesions $\left(\mathrm{SUV}_{\max } 5.9 \pm 3.4\right)$ was greater than that in inflammatory lesions $\left(\mathrm{SUV}_{\max } 2.2 \pm 0.03\right)$ at $28 \mathrm{~min}(P<$ 0.05).

In our analysis, the S-PSA level correlated strongly with the number of metabolically active lesions to be detected on PET. Additionally, there was a moderate negative correlation between PDT and number of lesions and a weak negative correlation between PDT and tumor activity on PET ( $\left.\mathrm{SUV}_{\max }\right)$. There was not any statistically significant difference between $\mathrm{S}$-PSA values in groups of patients with negative and positive scans.

However, the PDT in patients with positive findings comparing to negative ones was statistically significantly shorter $3.25 \pm 2.09$ months versus $31.2 \pm 22.02$ months, $P \leq 0.0001$. In the work of Ceci et al. [12], in patients with relapse, detected by $\left[{ }^{11} \mathrm{C}\right]$-choline PET/CT, the median PSA doubling time was 3.5 months and the mean PSA level was $9.08 \mu \mathrm{g} / \mathrm{L} \pm 5.1 \mu \mathrm{g} / \mathrm{L}$, with a range of $2-60 \mathrm{ng} / \mathrm{mL}$. In our analysis, the mean PSA level was $12.8 \pm 18 \mu \mathrm{g} / \mathrm{L}$ with a range of $0.62-69 \mu \mathrm{g} / \mathrm{L}$. From these results, it seems that the PSA doubling time is a more important prognostic factor than PSA level.

We know already from this preliminary experience that PSA levels can be low for positive scans. The patient in Figure 2 was definitely positive when PSA was 1.50 but doubtful already at the level 0.56 indicating the rapid repeated diagnostic procedure. In the literature, a $\left.{ }^{18} \mathrm{~F}\right]$-FACBC uptake in a pelvic lymph node on PET as a sign of biochemical relapse has been reported with a PSA level as low as $0.03 \mu \mathrm{g} / \mathrm{L}$ in a prostatectomized patient [13].

Anti-3- $\left[{ }^{18} \mathrm{~F}\right]$-FACBC demonstrated for disease detection in the prostate bed a sensitivity of $89 \%$ (32 of 36 patients), specificity of $67 \%$ ( 8 of 12 patients), and accuracy of $83 \%$ 


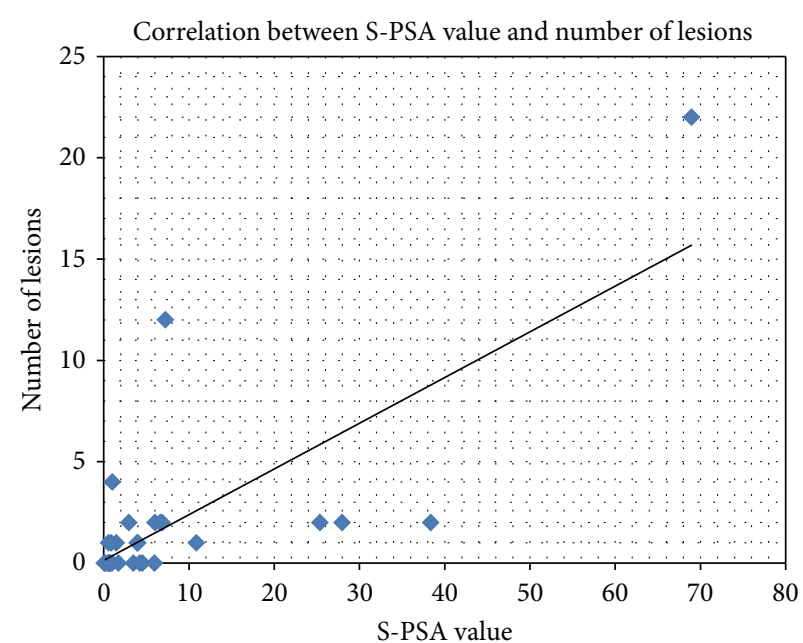

FACBC imaging — Regression line

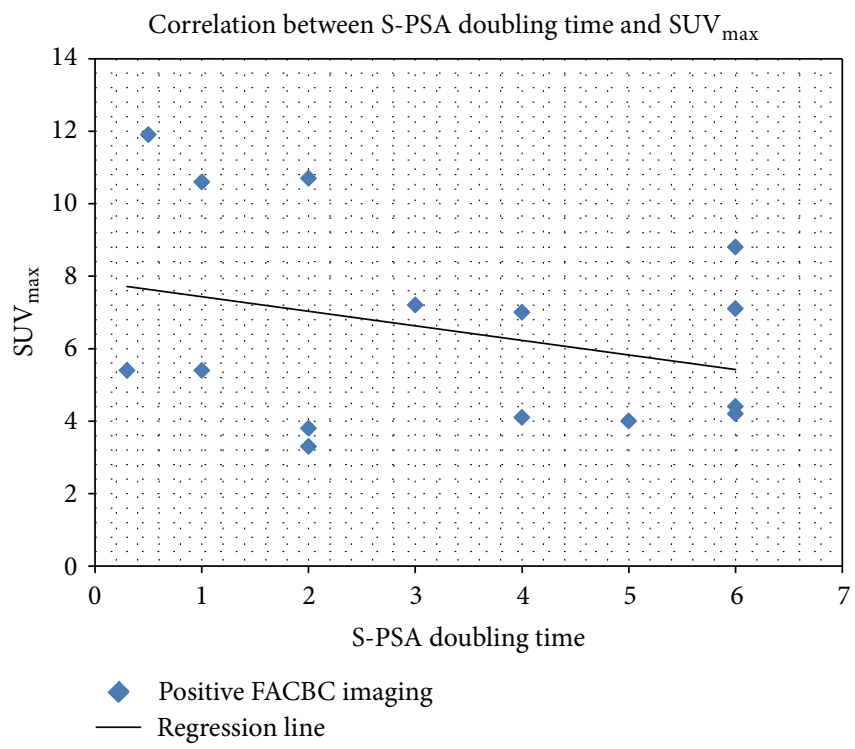

(b)

(a)

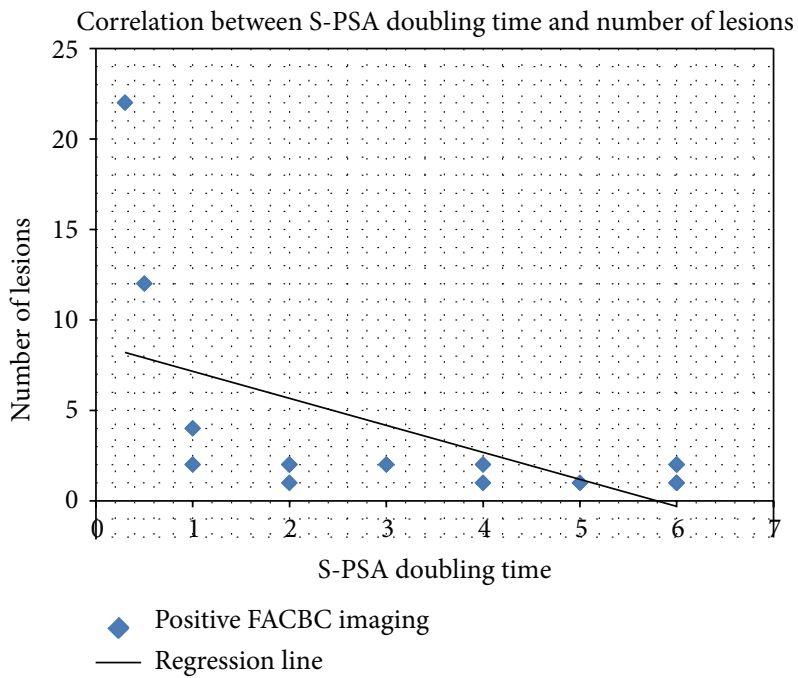

(c)

FIgURE 1: Correlations between the PSA value and the number of lesions (a), between S-PSA doubling time and SUV max of the FACBC study (b), and between the number of metabolically active lesions and the PSA doubling time (c) are shown schematically. There is a strong correlation between number of metabolically active lesions and PSA $(R=0.74)$ and weaker negative correlations between number of lesions and PSA-doubling time $(R=-0.56)$ and between SUV $_{\max }$ and PSA-doubling time $(R=-0.30)$.

(40 of 48 patients) [5]. In the detection of an extraprostatic recurrence, anti-3- $\left[{ }^{18} \mathrm{~F}\right]$-FACBC had a sensitivity of $100 \%(10$ of 10 patients) [5].

There is only one comparison in the literature, between $\left[{ }^{18} \mathrm{~F}\right]-\mathrm{FACBC}$ and $\left[{ }^{11} \mathrm{C}\right]$-choline, but no clear conclusions can be drawn $[6,7]$. The existing trends in the study favor FACBC in diagnosing prostate cancer. Anyhow, the radionuclides $\mathrm{C}-11$ and $\mathrm{F}-18$ have essential differences, for example, in chemical and physical characteristics. In order to understand the biochemical behavior better, FCH should be compared with FACBC in clinical trials, ideally. In the existing comparisons $[6,7]$, the patient preparation such as fasting time was a little bit different for different tracers; very few biopsies and surgeries were performed only in 5 patients and no statistical difference was found. Many patients had also androgen deprivation therapy on hold, but some had not $[6,7]$. $\left[{ }^{11} \mathrm{C}\right]$-choline has shown its capability in restaging studies in predicting prostate cancer survival in a large multicenter study in prostatectomized patients during androgen deprivation therapy [14].

In our material, very few patients were imaged with both $\left[{ }^{18} \mathrm{~F}\right]$-FACBC and $\left[{ }^{18} \mathrm{~F}\right]-\mathrm{FCH}$ within the 2 -week interval, but many patients had previous and follow-up $\left[{ }^{18} \mathrm{~F}\right]-\mathrm{FCH}-$ PET/CT studies with longer intervals. At least in two patients, we observed that some pharmaceuticals may influence the FCH uptake, but we have not yet seen any effect on FACBC 

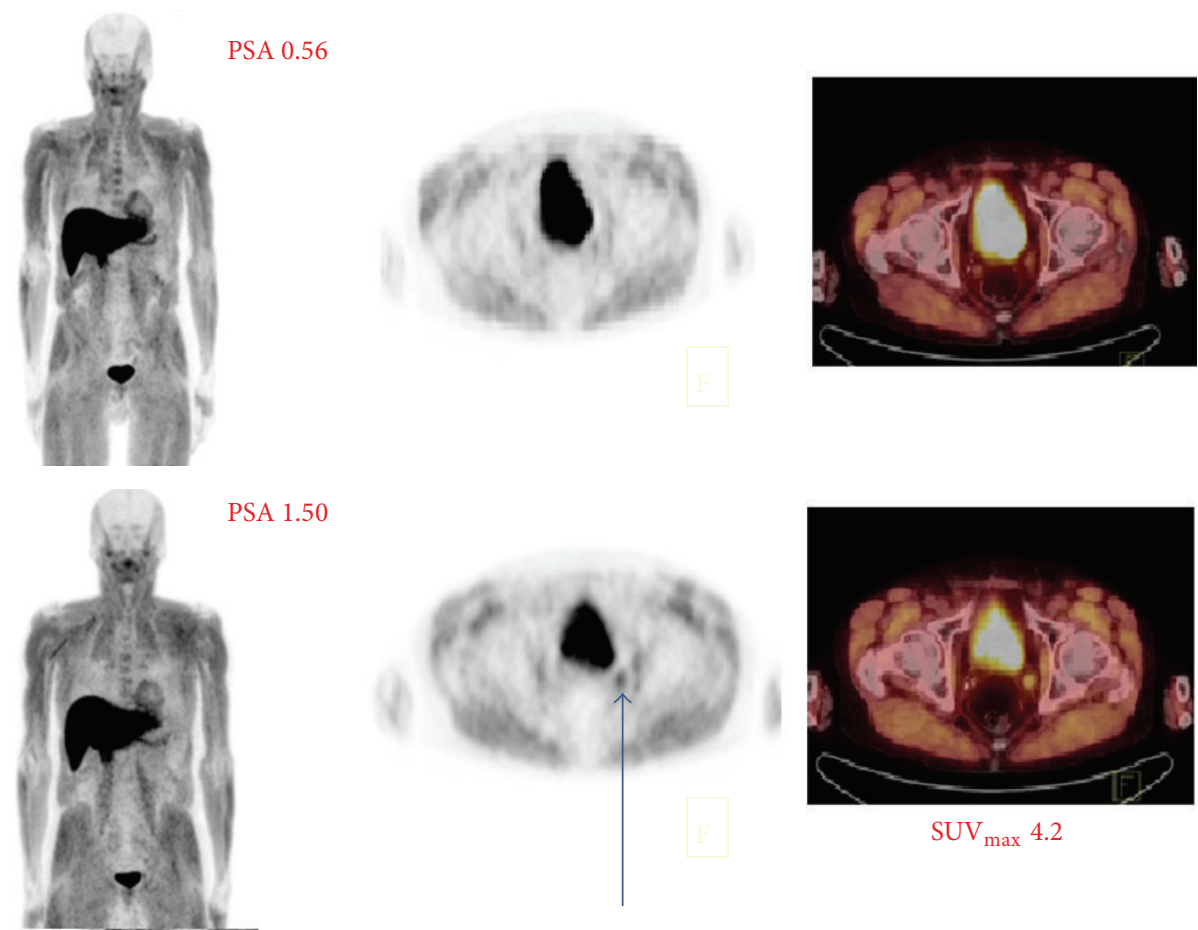

PSA 1.50
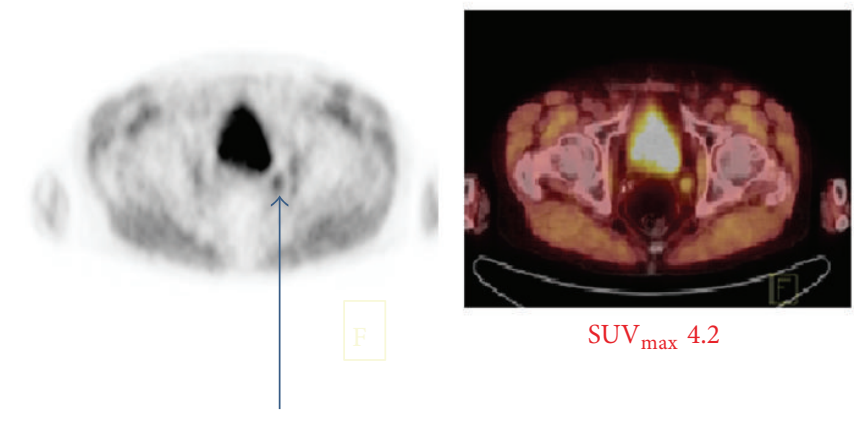

$\mathrm{SUV}_{\max } 4.2$

FiguRE 2: A 70-year-old patient had Gleason score 9 disease (T3bN0M0) treated with radical prostatectomy 6 years earlier and he developed a biochemical relapse. The first investigation was negative at serum PSA concentration 0.56, but, in the second examination 3 months later at PSA concentration 1.50, a small lymph node uptake was found in an obturator lymph node $\left(\mathrm{SUV}_{\max } 4.2\right)$; retrospectively, there was no significant uptake $\left(\mathrm{SUV}_{\max }\right.$ 1.7) in the first scanning. Normal distribution is seen in the liver, pancreas, skeletal muscles, and also in the urinary bladder.
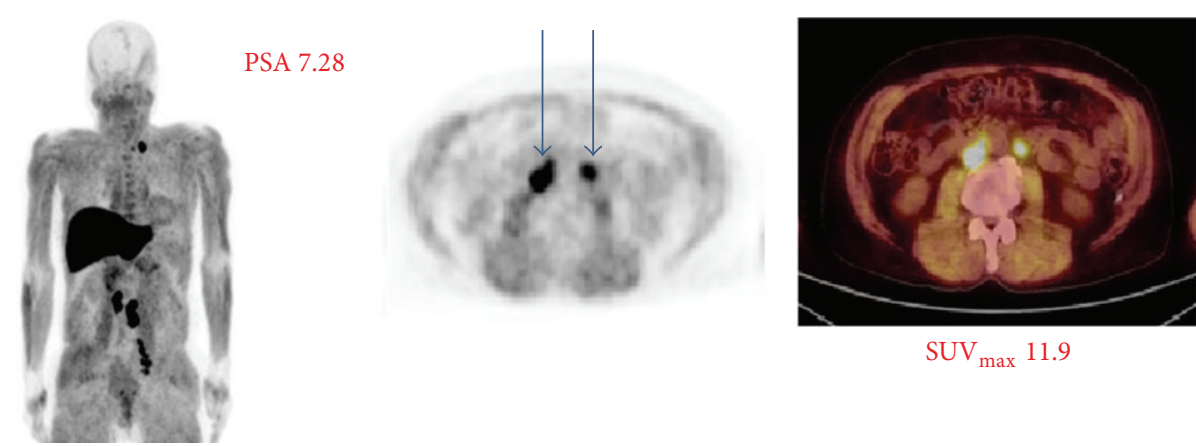

$\mathrm{SUV}_{\max } 11.9$
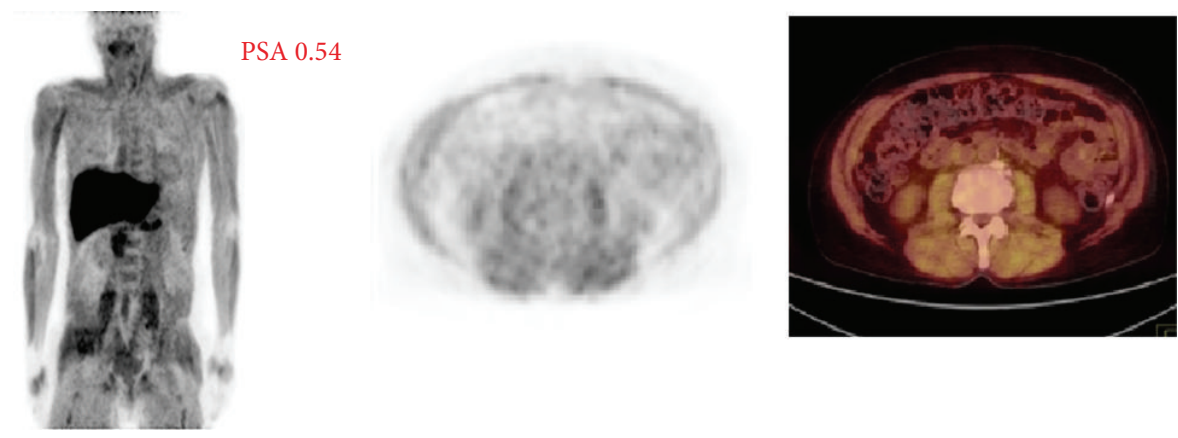

FIGURE 3: 67-year-old patient had Gleason score 9 disease (T4N1M1) treated originally with a radiation therapy 4 years earlier. After that, he had antiandrogen treatment but developed a biochemical relapse. The first examination was positive at serum PSA concentration 7.28, but, in the second scanning 3 months later, became negative when the PSA concentration was 0.54 . The first imaging demonstrated a large tumor burden in left iliac, para-aortic, aortocaval, and left supraclavicular lymph nodes; $S_{U V}$ max levels were up to 11.9. All these lymph node uptakes disappeared in 3 months as a treatment response to chemotherapy, and no pathologic findings were seen in the second imaging. 
uptake. Some of these effects with $\mathrm{FCH}$ have been reported [15]. We had two patients with false positive $\left[{ }^{18} \mathrm{~F}\right]$-FACBC findings in the prostate. Both patients (patients 23 and 26, Table 1) had negative findings in all 12 prostate biopsies interpreted as inflammatory and reactive changes to EBRT and all immunohistochemical staining for prostate cancer were negative. Patient 23 was negative in $\left[{ }^{18} \mathrm{~F}\right]-\mathrm{FCH}-\mathrm{PET}$ study two months earlier.

From our experience, the regular distribution of $\left[{ }^{18} \mathrm{~F}\right]-$ FACBC in man demonstrating an intense uptake in the pancreas and in the liver and a lesser activity in the bone marrow is actually almost ideal for prostate cancer detection, because these regions are usually free from the disease in early stage. Sometimes, skeletal muscle uptake may disturb differential diagnosis, but delayed imaging may help. The optimal time for highest tumor/nontumor ratio is at $28 \mathrm{~min}$ as reported by [3]. Urinary clearance appears seldom, even though a little urinary excretion is seen like in our patient in Figure 2.

From this preliminary data, we conclude that $\left[{ }^{18} \mathrm{~F}\right]-$ FACBC-PET may play a role in in vivo staging of an active prostate cancer. Although, according to our preliminary experience, there was no statistically significant difference in PSA level between the patients with positive and negative findings; short PSA doubling time may be indicator for a PET/CT study. We are aiming to use $\left[{ }^{18} \mathrm{~F}\right]$-FACBC-PET in dose planning for external beam radiation therapy and in normal diagnostic staging procedures, especially in restaging of biochemical relapse.

\section{Conflict of Interests}

The authors declare that there is no conflict of interests regarding the publication of this paper.

\section{References}

[1] J. A. Nye, D. M. Schuster, W. Yu, V. M. Camp, M. M. Goodman, and J. R. Votaw, "Biodistribution and radiation dosimetry of the synthetic nonmetabolized amino acid analogue anti- 18FFACBC in humans," Journal of Nuclear Medicine, vol. 48, no. 6, pp. 1017-1020, 2007.

[2] J. Sörensen, R. Owenius, M. Lax, and S. Johansson, "Regional distribution and kinetics of $[18 \mathrm{~F}]$ fluciclovine (anti-[18F] FACBC), a tracer of amino acid transport, in subjects with primary prostate cancer," European Journal of Nuclear Medicine and Molecular Imaging, vol. 40, no. 3, pp. 394-402, 2013.

[3] D. M. Schuster, P. A. Taleghani, P. T. Nieh et al., "Characterization of primary prostate carcinoma by anti-1-amino2-[(18)F] -fluorocyclobutane-1-carboxylic acid (anti-3-[(18)F] FACBC) uptake," The American Journal of Nuclear Medicine and Molecular, vol. 3, no. 1, pp. 85-96, 2013.

[4] R. Amzat, P. Taleghani, D. L. Miller et al., "Pilot study of the utility of the synthetic PET amino-acid radiotracer anti-1-amino3-[18F]fluorocyclobutane-1-carboxylic acid for the noninvasive imaging of pulmonary lesions," Molecular Imaging and Biology, vol. 15, no. 5, pp. 633-643, 2013.
[5] D. M. Schuster, B. Savir-Baruch, P. T. Nieh et al., "Detection of recurrent prostate carcinoma with anti-1-amino-318F-fluorocyclobutane-1-carboxylic acid PET/CT and 111Incapromab pendetide SPECT/CT,' Radiology, vol. 259, no. 3, pp. 852-861, 2011.

[6] C. Nanni, R. Schiavina, S. Boschi et al., "Comparison of 18FFACBC and $11 \mathrm{C}$-choline PET/CT in patients with radically treated prostate cancer and biochemical relapse: preliminary results," European Journal of Nuclear Medicine and Molecular Imaging, vol. 40, supplement 1, pp. S11-S17, 2013.

[7] C. Nanni, R. Schiavina, E. Brunocilla et al., "18F-FACBC compared with 11C-Choline PET/CT in patients with biochemical relapse after radical prostatectomy: a prospective study in 28 patients," Clinical Genitourinary Cancer, vol. 12, no. 2, pp. 106110,2014

[8] S. Oka, R. Hattori, F. Kurosaki et al., "A preliminary study of anti-1-amino-3-18f-fluorocyclobutyl-1- carboxylic acid for the detection of prostate cancer," Journal of Nuclear Medicine, vol. 48, no. 1, pp. 46-55, 2007.

[9] F. E. von Eyben and K. Kairemo, "Meta-analysis of 11C-choline and 18F-choline PET/CT for management of patients with prostate cancer," Nuclear Medicine Communications, vol. 35, no. 3, pp. 221-230, 2014

[10] H. Okudaira, N. Shikano, R. Nishii et al., "Putative transport mechanism and intracellular fate of trans-1-amino-3-18Ffluorocyclobutanecarboxylic acid in human prostate cancer," Journal of Nuclear Medicine, vol. 52, no. 5, pp. 822-829, 2011.

[11] P. Castellucci and H. Jadvar, "PET/CT in prostate cancer: Noncholine radiopharmaceuticals," Quarterly Journal of Nuclear Medicine and Molecular Imaging, vol. 56, no. 4, pp. 367-374, 2012.

[12] F. Ceci, P. Castellucci, T. Graziani et al., "11C-Choline PET/CT detects the site of relapse in the majority of prostate cancer patients showing biochemical recurrence after EBRT,' European Journal of Nuclear Medicine and Molecular Imaging, vol. 41, no. 5, pp. 878-886, 2014.

[13] F. E. von Eyben, A. Kangasmäki, T. Kiljunen, and T. Joensuu, "Volumetric-modulated arc therapy for a pelvic lymph node metastasis from prostate cancer: a case report," Tumori, vol. 99, no. 3, pp. el20-e123, 2013.

[14] G. Giovacchini, M. Picchio, R. Garcia-Parra et al., "11C-Choline $\mathrm{PET} / \mathrm{CT}$ predicts prostate cancer-specific survival in patients with biochemical failure during androgen-deprivation therapy," Journal of Nuclear Medicine, vol. 55, no. 2, pp. 233-241, 2014.

[15] M. Beheshti, S. Haim, R. Zakavi et al., "Impact of 18Fcholine PET/CT in prostate cancer patients with biochemical recurrence: influence of androgen deprivation therapy and correlation with PSA kinetics," Journal of Nuclear Medicine, vol. 54, no. 6, pp. 833-840, 2013. 


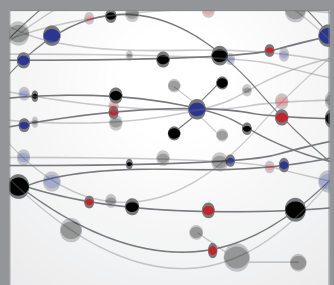

The Scientific World Journal
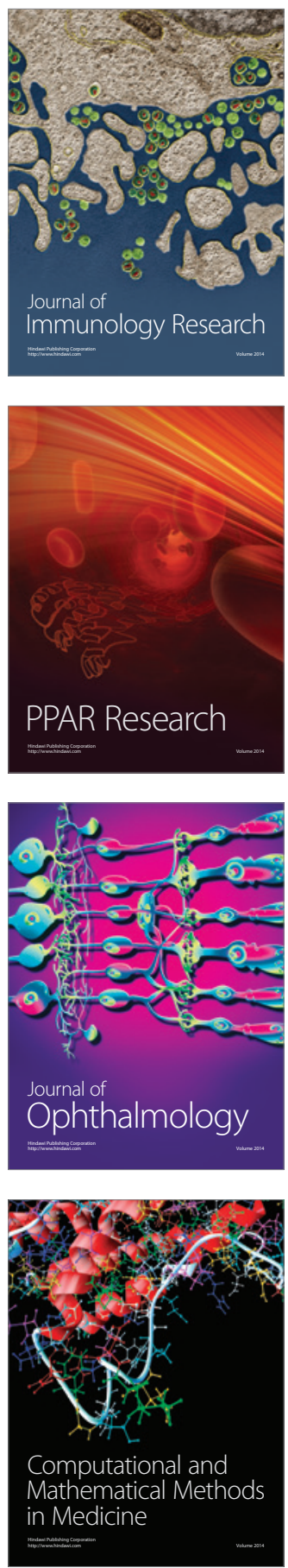

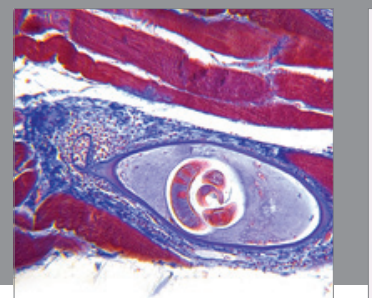

Gastroenterology

Research and Practice
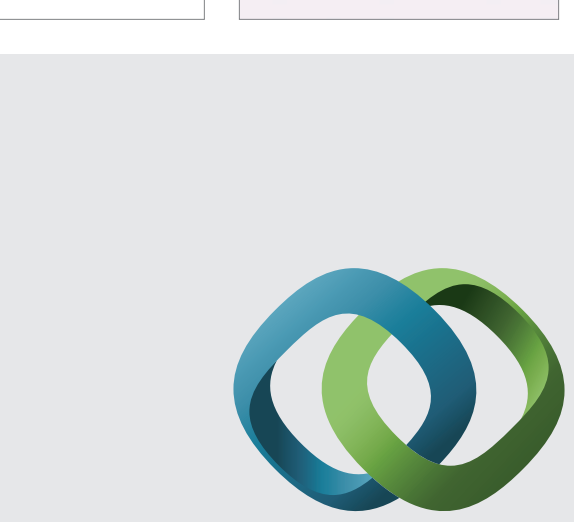

\section{Hindawi}

Submit your manuscripts at

http://www.hindawi.com
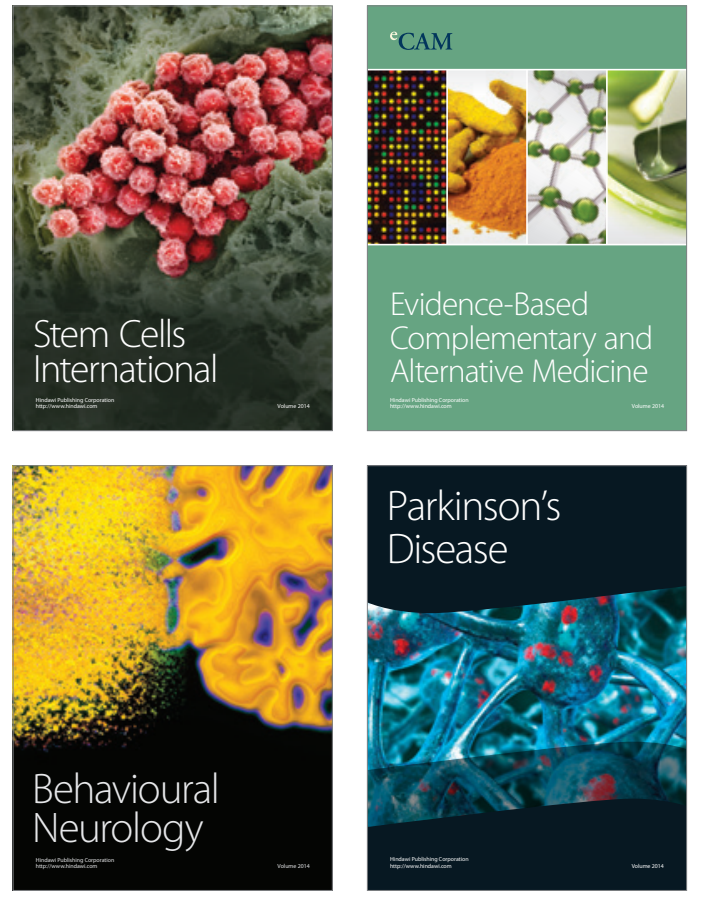
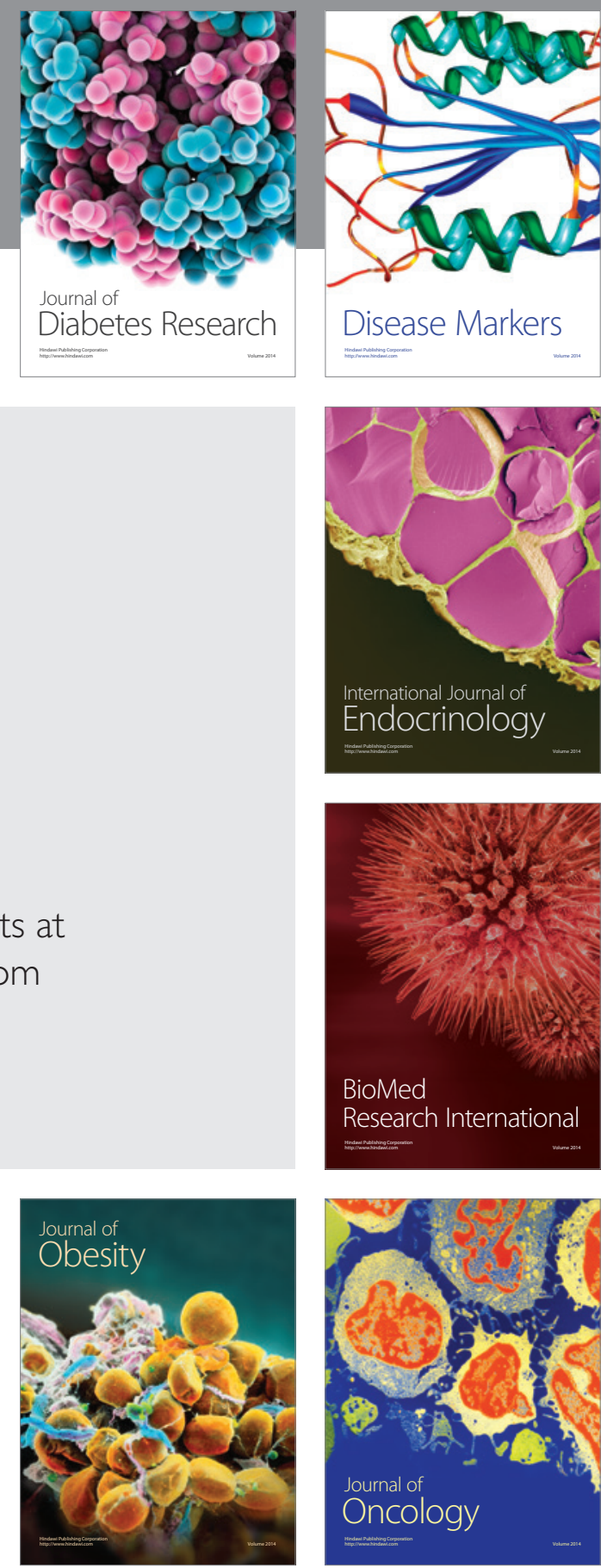

Disease Markers
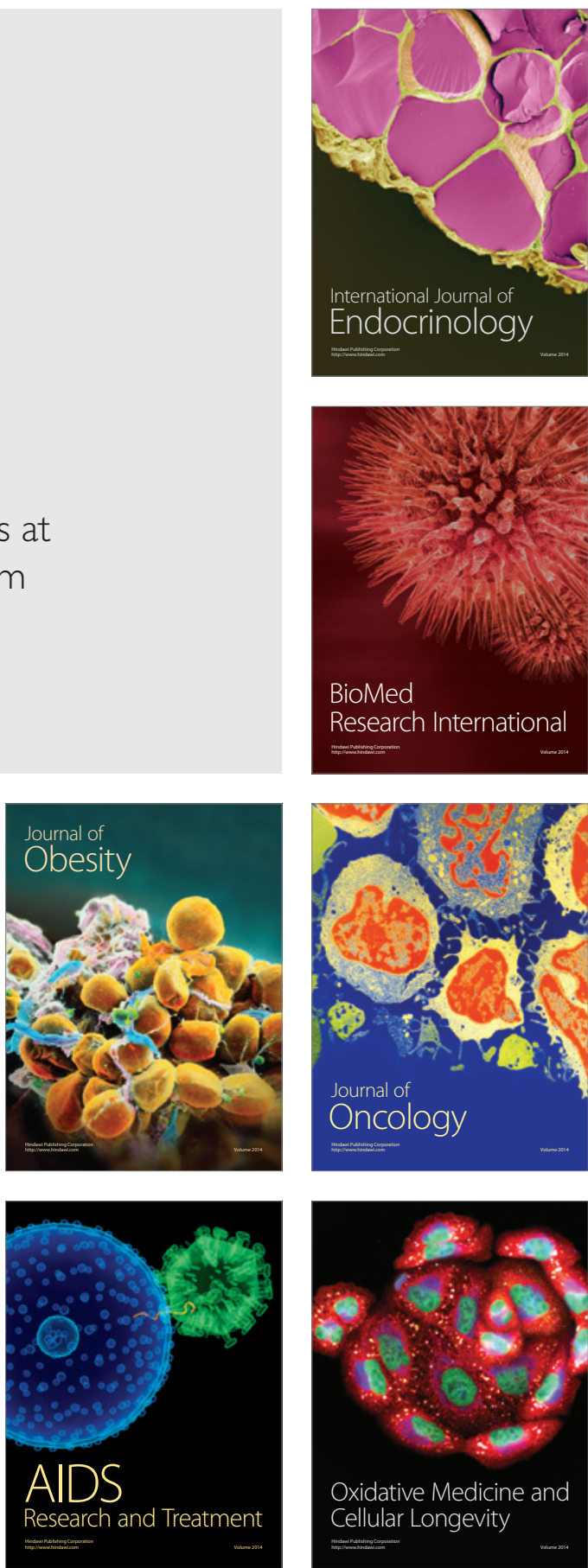